\title{
BRASÍLIA, UMA CIDADE COMO AS OUTRAS? epresentações sociais e práticas de violência
}

\author{
Maria Stela Grossi Porto*
}

Resumo: Privilegiar a análise das representações sociais significa reconhecer sua importância teórico-metodológica como estratégia de conhecimento do social. Considerando a temática da qual se ocupa, o artigo explicita a pertinência da Teoria das Representações Sociais como possibilidade de análise do fenômeno da violência contemporânea, assumindo ser impossível compreendê-lo sem se interrogar sobre sentidos, valores e crenças que estruturam e presidem a vida social. O texto ressalta a importância de que políticas públicas de segurança levem em consideração significações e sentidos, de natureza subjetiva, expressos nas Representações Sociais, elaboradas e produzidas não apenas pelos integrantes da área de segurança pública mas, igualmente, por aqueles que direta ou indiretamente se beneficiam ou sofrem as conseqüências de seus acertos ou desacertos, ou seja, a sociedade, em seus distintos segmentos. Em outras palavras, através da utilização de evidências empíricas, aponta-se a pertinência de inserir a temática das representações sociais e de seus conteúdos no horizonte das preocupações dos formuladores de política. O Distrito Federal é o universo empírico que dá suporte às análises realizadas.

Palavras-chave: práticas e representações sociais; segurança pública; violência; medo; Distrito Federal.

\section{Introdução}

Articulando práticas e representações sociais da violência, o artigo concentra suas reflexões em questões de caráter mais analítico e gerais, ligadas a dados empíricos, circunscritos ao Distrito Federal.

\footnotetext{
* Departamento de Sociologia UnB.

Trabalho elaborado a partir de pesquisa apoiada pelo CNPq. Artigo recebido em 20 out. 2009 e aprovado em 23 out. 2009.
} 
Parece não fugir às características do Distrito Federal uma constatação que vem se tornando recorrente para outros espaços urbanos e diz respeito à questão da violência, de seu crescimento e de sua relevância no contexto urbano brasileiro, seja nas grandes metrópoles seja, igualmente, nas cidades de médio e até mesmo de pequeno porte - em síntese, fala-se de violência como de uma questão endêmica. A idéia de violência, e de seu crescimento, vai se traduzindo em um clamor por segurança pública entendida como sinônimo de um conjunto de medidas, ações e intervenções da ordem estatal que possam reduzir esta violência, conduzindo a sociedade a padrões mais solidários de convivência. Mitos, verdades e equívocos percorrem diferentes imaginários sociais e representam violência e segurança como fenômenos entrelaçados, sendo a violência o fantasma, cada vez mais presente, que afronta e põe em risco a segurança, pensada, nesse sentido, como política pública e diagnosticada como em situação de crise (Porto, 2009 b).

A capital da República figura aqui como referência empírica com o objetivo de ressaltar, problematizando-as, determinadas representações sociais da violência. Inicialmente, proponho-me a problematizar análises que têm centrado as explicações do fenômeno unicamente na variável econômica, insistindo em representações que têm Brasília como cenário por excelência de violências protagonizadas por atores oriundos de camadas economicamente privilegiadas, ligados, quase sempre, ao “mundo político oficial”. São representações que, de algum modo, invertem a relação estereotipada entre pobreza/violência, não para negá-la (já que ela também tem vigência em outras representações), mas para apontar o que consideram ser uma "especificidade" da cidade. Não minimizando a existência de relações causais entre economia e violência (que na literatura especializada tem sido prioritariamente tratada a partir da análise das relações entre pobreza e violência e que não serão aqui objeto de tratamento conceitual), ${ }^{1}$ busca-se qualificar um pouco melhor a natureza dessas relações de modo a percebê-las em um 
contexto mais complexo, realçando dimensões culturais, simbólicas e, portanto, valorativas que desempenham, igualmente, um papel relevante para se compor um panorama explicativo da incidência da violência, sobretudo em sua vertente urbana. Para tanto, atenho-me a manifestações de violência protagonizadas por jovens de camadas economicamente privilegiadas do Distrito Federal, para os quais a sobrevivência e a exclusão material não se colocam como problema. A seguir, reflito, igualmente, sobre práticas e representações de violência protagonizadas por outros atores sociais, institucionais ou membros da sociedade civil.

Considerando o conteúdo deste dossiê, que se beneficia da preciosa participação dos autores mesmos da Teoria de Representações Sociais, não vou retomar o histórico da constituição desta teoria; limito-me, a tratar de forma breve a explicitação da apreensão sociológica que dela tenho feito.

\section{Trabalhando com representações sociais ${ }^{2}$}

A noção de Representações Coletivas surgiu com Durkheim, nos primórdios da constituição da Sociologia como ciência. Posteriormente, foi re-trabalhada, re-visitada e sistematizada pela Psicologia Social, mais precisamente por Moscovici, autor da teoria por ele re-batizada como Teoria das Representações Sociais (TRS). Moscovici foi, juntamente com Jodelet, responsável pela contemporânea retomada da noção (Porto, 2009). Segundo Moscovici ( 2003, p. 79),

a teoria das representações sociais toma como ponto de partida a diversidade dos indivíduos, atitudes e fenômenos, em toda sua estranheza e imprevisibilidade. Seu objetivo é descobrir como indivíduos e grupos podem construir um mundo estável, previsível, a partir da diversidade. 
Para Denise Jodelet (2001, p. 22), a representação social "é uma forma de conhecimento, socialmente elaborada e partilhada, com um objetivo prático, que contribui para a construção de uma realidade comum a um conjunto social”.

Na Psicologia Social, Moscovici (1989, 2003) e Jodelet (2001) são os autores que têm insistido na necessidade que sentem os indivíduos de explicarem o mundo e se explicarem neste mundo (no qual estão inseridos). Ensina Jodelet (2001, p. 17): "Frente a esse mundo de objetos, pessoas acontecimentos ou idéias, não somos (apenas) automatismos, nem estamos isolados num vazio social: partilhamos esse mundo com os outros, que nos servem de apoio, às vezes de forma convergente, outras pelo conflito, para compreendê-lo, administrá-lo ou enfrentá-lo". Adverte, ainda, que esse conhecimento, orientando condutas, contribui para criar a realidade da qual fala e sobre a qual se refere.

É a partir destas contribuições que venho utilizando a TRS em benefício da compreensão sociológica. Para não invadir área que não é competência precípua da Sociologia, devo ressaltar que a apropriação que aqui se faz da noção tem, em certo sentido, um objetivo utilitário: não percorre passo a passo o caminho apontado por aqueles que, na Psicologia Social, se dedicaram ao tema, nem privilegia a parte da teoria que se atém aos aspectos propriamente cognitivos da formação e da constituição das representações sociais e de seus mecanismos de difusão. A noção é trabalhada como um todo, assumindo as representações sociais enquanto blocos de sentido articulado em sintonia, em oposição, em competição ou coexistindo simplesmente junto a outros blocos de sentido, compondo uma teia ou rede de significações que permite ao analista avançar no conhecimento da sociedade por ele analisada (Porto, 2009).

O enfoque sociológico que privilegia a análise da TRS para refletir sobre questões ligadas à violência e ao medo fundamenta- 
se, pois, no reconhecimento da importância teórico-metodológica desta teoria, enquanto caminho para o conhecimento do social. As representações sociais expressam visões de mundo que objetivam explicar e dar sentido aos fenômenos dos quais se ocupam, ao mesmo tempo em que, pela condição de representação social, participam da constituição desses mesmos fenômenos. Ou seja, conforme Michaud (1996, p. 41), admite-se uma solidariedade entre fenômeno e representação social:

[...] existe atualmente uma conexão substantiva entre a contribuição real de situações e eventos no mundo e o saber que sobre eles temos ou acreditamos ter. A solidariedade entre evento e representação do evento é total. Isso não significa, contrariamente ao que diz Baudrillard, que somente existe simulacro e que a realidade foi totalmente descartada. Não, de modo mais complexo, trata-se, ao invés, do fato de que os vínculos entre realidade e representação da realidade são impossíveis de serem desfeitos.

Tais características apontam para a pertinência de se tratar a análise da violência por intermédio da teoria das representações sociais, ressaltando dois de seus aspectos fundamentais, quais sejam, as relações entre a violência e suas representações e a possibilidade de captar a racionalidade presente nas crenças coletivas e em suas significações, aí compreendidos ideologias, ditados, conhecimentos populares e senso comum, desde que submetidos à análise científica.

Admite-se que as representações sociais, embora resultado de experiências individuais, são condicionadas e, nesse sentido, dependentes das inserções sociais dos indivíduos que as produzem. Ou seja, indivíduo e sociedade configuram uma relação de mútua dependência, tanto conflituosa quanto harmoniosa. Não seria de todo impertinente lembrar o argumento weberiano a propósito de "afinidades eletivas" ao analisar as relações entre a Ética protestante e o espírito do Capitalismo (Weber, 2004, p. 83, 126). 
Essa perspectiva analítica permite considerar tanto a experiência subjetiva dos atores (protagonistas ou vítimas de violência) quanto a objetividade do sistema (contexto, ambiente ou situação) no qual ações violentas são praticadas. Significa pesquisar os indivíduos e o ambiente (estruturas) no qual tais indivíduos atuam. É também privilegiar a subjetividade das representações sabendo, no entanto, que elas só se constroem em relação a um dado contexto ou ambiente objetivamente dado, já que os sentidos não podem ser compreendidos independentemente do campo social no qual se inserem.

Tal enfoque aponta também a contribuição substantiva que crenças, ditados populares e ideologias, tomados em sua condição de representações sociais, aportam ao conhecimento do social, descartando, pois, sua definição como algo irracional, ausente de vínculos lógicos com o real. Nessa medida, vale insistir, as representações sociais, em si mesmas, não são nem falsas nem verdadeiras, apenas a matéria-prima, o dado bruto que cabe ao sociólogo analisar, interpretar, compreender. Além disso, não são racionais ou irracionais embora respondam, certamente, por uma racionalidade que as constitui em objeto do conhecimento. Racionalidade de uma natureza distinta totalmente do conhecimento que a ciência proporciona. Para o analista do social, tal produto não pode ser sinônimo do real e sim um dado de realidade que precisa ser submetido à análise como condição de produção de um conhecimento pertinente.

Essa afirmação é tanto mais válida se se considera que, na condição de máximas, ditados populares, crenças, etc, as representações sociais são conteúdos orientadores de conduta, sobretudo quando implicam valores e normas. Aqui também vale a afirmação segundo a qual ação social e representação social são fenômenos solidários: as subjetividades presentes nas representações da violência interferem, direta ou indiretamente, nos processos de 
organização das ações e relações sociais, ou seja, nos espaços nos quais o social se produz e se reproduz como espaço de interação.

Um outro esclarecimento introdutório: tal apropriação se insere no contexto de uma discussão de natureza metodológica e tem como pressuposto que, por meio dessa análise, pode ser viável avançar o conhecimento sobre um dado fenômeno, no caso o da violência.

Resumindo as considerações acima, explicito, através da utilização de um texto anterior, os pressupostos de caráter metodológico que informam essa abordagem:

as Representações Sociais: a) embora resultado da experiência individual, (...) são condicionadas pelo tipo de inserção social dos indivíduos que as produzem; b) expressam visões de mundo objetivando explicar e dar sentido aos fenômenos dos quais se ocupam, ao mesmo tempo em que c) por sua condição de representação social, participam da constituição desses mesmos fenômenos; d) por expressarem visões de mundo, dando sentido e explicação aos fenômenos, apresentam-se, em sua função prática, como máximas orientadoras de conduta; e) como decorrência de serem constitutivas dos fenômenos representados, configuram a existência de uma conexão de sentido (solidariedade) entre os fenômenos e suas representações sociais, que, portanto, não são nem falsas nem verdadeiras mas a matéria-prima do fazer sociológico. (Porto, 2009).

Como ressaltado na introdução, Brasília se coloca como um objeto pertinente de indagação por ser representada por muitos população em geral e também, periodicamente, pela mídia e seus analistas -, como cidade a-típica por suas características históricas e políticas, características estas que por fugirem aos propósitos do artigo não serão aqui detalhadas. ${ }^{3}$

Esta imagem de a-tipicidade sobressai, por exemplo, no que diz respeito à variável econômica, acima mencionada, em suas relações com a violência. Inúmeras representações insistem no 
caráter das manifestações de violência que atingem - como vítimas ou protagonistas - integrantes das camadas sociais economicamente privilegiadas da sociedade brasiliense, minimizando (mas não negando, como já ressaltado) outras dimensões igualmente relevantes da violência, como, por exemplo, as múltiplas manifestações de violências inter-pessoais que atingem anonimamente distintos estratos da população e aos quais o artigo se refere mais abaixo. Em função de tais características, explicar ou compreender tais atos de violência constitui um desafio, dentre os muitos que têm provocado, na atualidade, a imaginação sociológica seja no sentido de desvendar representações estigmatizantes produzidas sobre a capital federal, seja buscando articulá-las com as possíveis raízes e determinantes das violências igualmente presentes em outros espaços sociais e simbólicos.

\section{Das representações e das práticas: a realidade do Distrito Federal ${ }^{4}$}

Por que manifestações de violência protagonizadas por membros de camadas socioeconômicas privilegiadas amedrontam, chocam e assustam segmentos importantes da população, em proporções talvez maiores do que outras formas de violência que, igualmente, inundam os conteúdos da mídia? É certo que as representações sociais têm muito a dizer.

Para responder de forma um tanto direta e rápida à questão, avançaria como hipótese que tais manifestações parecem expor algumas dimensões da violência que o senso comum e as representações sociais dele diretamente importadas dele se acostumaram a associar unicamente ao cotidiano das camadas pobres, dos excluídos e deserdados da sorte, das "classes perigosas" (Chevalier, 1974), daqueles que, nessa avaliação, "topam tudo por dinheiro", inclusive matar, se for em troca da sobrevivência. 
Percebida sob esse ângulo, a mudança de endereço da violência ou sua chegada a endereços considerados até então "insuspeitos" e direcionada a vítimas "impensadas" e "impensáveis" causaria espanto, choque, pânico e paralisia, junto com curiosidade, análises, discussões e, por vezes, um consumo um tanto mórbido desse tipo de notícia que tem pautado não apenas os meios de massa ditos sensacionalistas mas o conjunto da mídia, em suas múltiplas modalidades falada, escrita e televisiva.

Essa nova (?) violência, assim retratada e exposta, torna-se tão excessivamente visível que, se por um lado, é banalizada no sentido de sua repetição, por outro, no entanto, é politizada à medida que, deixando de frequentar as páginas policiais de notícias da periferia para comparecer timidamente na mídia associada a endereços ditos nobres, parece se apresentar e ser percebida como problema social ou como problema de política social, tornando-se objeto de frequentes representações sociais.

Aqui parece pertinente recorrer à análise que Jodelet oferece, como exemplo, do surgimento de uma representação social: trata-se do fenômeno da Aids. Assim se expressa a autora:

A mídia e as pessoas se apoderaram deste mal desconhecido e estranho, cuja proximidade ainda não tinha sido revelada. A ausência de referências médicas favoreceu uma qualificação social da doença, mesmo com a permissão da análise do discurso da mídia na observação de uma rápida conjugação do progresso de conhecimentos científicos e de imagens construídas no espaço público, em torno da Aids e de suas vítimas. (Jodelet, 2001, p. 18).

E mais à frente continua:

Um acontecimento surge no horizonte social, que não se pode mostrar indiferente: mobiliza medo, atenção e uma atividade cognitiva para compreendê-lo, dominá-lo e dele se defender. A falta de informação e a incerteza da ciência favorecem o surgimento de representações que vão circular de boca em boca ou pular de um veículo de comunicação a outro. (Jodelet, 2001, p. 20). 
Para o contexto brasileiro, valeria a única ressalva de que, perante a nova (?) violência, o que se coloca não é, propriamente, ausência de informação, mas, talvez, o excesso de informação não qualificada, ruídos, já construídos como representação.

Várias representações, tais como a de volta à barbárie e ao estado de natureza, além de outros estereótipos e lugares-comuns, foram e têm sido evocadas pelo senso comum para diagnosticar essas novas (?) formas de violência na contemporaneidade brasileira (Brasília como cidade exemplar) e para demandar das autoridades de segurança pública medidas e ações pertinentes. Ou seja, sua representação com magnitude e visibilidade crescente contribui para produzir um imaginário de insegurança e de medo, aliado à sensação de ameaça. Esse cenário auxiliaria a compreensão, em certo sentido, das razões dessas novas (?) modalidades de violência estarem se transformando em assunto recorrente para estudiosos e em possíveis alvos (reais ou desejados) de políticas públicas. Explicaria, igualmente, as razões de se constituírem em objetos de avaliação por parte de segmentos sociais que, percebendo-se acuados no espaço onde até então costumavam se refugiar dos perigos "externos" ou seja, o ambiente doméstico, transformado em espaço de violência ou em abrigo de prováveis assassinos, se demandam de forma recorrente: o que está acontecendo e como mudar essa situação? quem deve ser responsabilizado, a família, a sociedade ou o Estado?

Por atingirem camadas privilegiadas da sociedade, essas manifestações de enorme crueldade e violência, embora relativamente tópicas e episódicas (se imaginarmos que a grande maioria dos jovens brasilienses está longe da opção por uma carreira de violência e crimes), são representadas como crescentemente recorrentes.

Visando situar o contexto empírico que é objeto de minhas reflexões, destacaria alguns exemplos das manifestações de violência que, de algum modo, tiveram Brasília como palco e estão, ainda, 
presentes nos imaginários e nos noticiários do país: o assassinato do índio pataxó, ${ }^{5}$ o espancamento de jovens até a morte - sendo os casos de Marco Antônio Velásquez, João Cláudio Cardoso Leal e Rodrigo Toledo de Aguiar ${ }^{6}$ bastante conhecidos - e a morte, também por espancamento, de um garçom em Porto Seguro, na Bahia, ${ }^{7}$ episódios cujo denominador comum é o fato de terem sido praticados por jovens de camadas médias ou abastadas de Brasília contra vítimas indefesas. Dentre essas vítimas, alguns eram jovens, da mesma origem social dos agressores, outros, como o índio pataxó e o garçom de Porto Seguro, cidadãos adultos de origem sociocultural e econômica distinta da de seus algozes.

A depender do ponto de vista, ou dos paradigmas de quem as formula, as respostas às perguntas acima arroladas vêm na forma de representações sociais quase sempre polarizadas, já que enfatizam ora uma ora outra, dentre algumas das possíveis causas percebidas como disponíveis para pensar a violência urbana, com ênfase para a responsabilização do indivíduo ou da sociedade, mas sempre, ou quase sempre, tendo como pressuposto que tais ocorrências são aqui mais comuns por terem como protagonistas os "filhinhos de papai", políticos em geral cujos atos ficam impunes.

Priorizar uma ou outra das causas (formuladas como representações) explicativas do fenômeno - ator ou sistema - mesmo correndo o risco de um diagnóstico unilateral diante da realidade plural e polissêmica, como é a da violência, em uma sociedade complexa, diferenciada, desigual e hierárquica como a brasileira, corresponderia, para aqueles que as formulam, à necessidade de compreender esse fenômeno novo, incorporando-o de alguma forma ao rol dos saberes disponíveis e interiorizados, ainda que ele subverta as representações e estigmas tidos, até então, como verdade sobre quem são os atores e quem são as vítimas de violência. Nos dizeres de Moscovici (2003, p. 54), "a finalidade de todas as representações é tornar familiar algo não familiar, ou a própria não familiaridade". 
Quando se analisa o fenômeno sob a ótica dos jovens economicamente privilegiados - e, como se pretende apontar, sob tal aspecto Brasília nada tem de diferente de outras metrópoles -, parece possível poder dizer que a necessidade de busca de "familiaridade" produz representações que têm insistido sobre sua ausência de limites e de responsabilidade, seu egoísmo desmedido e sua existência grupal ou tribal, alternativa por meio da qual todos até se admitem culpados de um ato violento e criminoso, mas ninguém se assume como individualmente responsável por ele. Pensadas sob a ótica dos pais, as representações apontam-nos como permissivos, liberais, incapazes de exercer autoridade ou de compartilhar afetos; ou, ainda, acusam-nos de repressores, distantes, ausentes, e aí caberia um etc., pois a lista tem tudo para se prolongar.

Selecionadas de modo unilateral e excludente, tais tentativas de compreensão (da violência) centradas tão-somente no indivíduo, ou em suas famílias ou, ainda, apenas na sociedade revelamse insuficientes e sem condições de atingir a complexidade do fenômeno. A sensibilidade sociológica pediria, por um lado, para que se refletisse sobre o binômio indivíduo/sociedade como polaridades dinâmicas; e por outro, que, a depender do contexto, o peso causal de idiossincrasias, perturbações pessoais, frustrações, neuroses e psicoses individuais poderá ter preponderância sobre os condicionamentos sociais. Microcosmo doente como expressão e parte de um macrocosmo também em processo de degeneração.

Para avançar o conhecimento sociológico, tais representações necessitam ser apreendidas pela análise como objeto e ponto de partida da investigação e não seu resultado. Neste sentido, para alguns dos crimes violentos acima descritos, parece pertinente falar de situações limites, nas quais as patologias individuais convivem com sociedades portadoras de síndromes que beiram igualmente ao patológico. Para se buscar (weberianamente) compreender mais do que explicar tais violências seria possível, talvez, apreendê-las como 
relações sociais caracterizadas por uma objetificação do outro, por sua negação enquanto sujeito, ao invés de, por um lado, apostar (como quer o senso comum) na desagregação familiar, no distanciamento entre pais e filhos, na inversão dos valores e, como uma de suas variantes, na convivência e na competição entre valores antagônicos e irreconciliáveis, no desregramento característico do caos urbano e, por outro, apontar (como solução de facilidade) para os indivíduos, imputando-lhes condutas desviantes e índole criminosa. Analisando estes episódios de violência de jovens, afirmei em texto anterior que, nesses contextos, os grupos ou gangues em que esses jovens se inserem não parecem constituir uma condição de solidariedade ou de pertencimento; ao invés, reafirmam expressões de individualismo, cujos portadores, fragilizados para se perceberem como identidades e para assumirem individualmente as conseqüências de seus atos, se movimentam e atuam em gangues ou grupos (Porto, 2000).

Em contextos desta natureza, está-se em presença de representações que cabe à Sociologia analisar, deixando como secundária sua condição de falsas ou verdadeiras. No âmbito do Distrito Federal tal análise requer, também, precaução contra os estereótipos que, em função das características históricas de sua ocupação (às quais, como já dito, não vamos nos ater), vão definila como um contexto atípico, único. Reforçando meu argumento contrário ao caráter atípico da capital federal, vale relembrar episódios de violência de jovens oriundos de camadas privilegiadas, ocorridos em outras metrópoles brasileiras: o caso do duplo parricídio, em novembro de 2002, dos Richthofen, casal abastado da cidade de São Paulo que envolve, como responsáveis, além de sua filha Suzane, de 19 anos, o namorado dela e o irmão desse, jovens estes oriundos de camadas sociais e estilos de vida distintos da cultura burguesa na qual foi educada a jovem Suzane; o do neto que, ainda em 2002, mata a avó e a empregada de uma família também pertencente às camadas média e rica de São Paulo; o de Jaques Chulam, autor, aos 35 anos, do livro recém-publicado (outubro de 2009 - Surfista, ex- 
drogado e ex-traficante) no qual retrata a saga dramática, iniciada aos 11 anos, no mundo das drogas, como consumidor e traficante e com passagem pela prisão em Portugal; por último, recorde-se a história tristemente famosa de Pedro Dom, jovem da zona sul carioca, que, após tornar-se consumidor de drogas, assaltante e assassino, foi morto num confronto com a polícia, em agosto de 2005 .

Da análise da violência urbana em Brasília - até aqui centrada mais especificamente em atores jovens e economicamente privilegiados - passo, agora, a considerar também outros grupos ou estratos da população do DF. Se a sessão menciona as práticas é por considerar sua intensa articulação com as representações sociais, objeto deste artigo. Se, sob certo aspecto, as manifestações de violência centradas na população jovem, aqui apresentadas, reforçam as recorrentes representações e diagnósticos da cidade como vivendo mergulhada na crise, porque terra de ninguém ou porque "os que contam", “os que são alguém", nomeados e reconhecidos, estão imunes à lei, sob outro ângulo - e estendendo o raciocínio a outros segmentos da população -, gostaria de lembrar episódios nos quais alguma manifestação brutal de violência, protagonizada por outros representantes da população civil (algumas vezes, igualmente, provenientes de estratos médios ou ricos) ou do aparato estatal, provocam estados de choque e/ou comoção popular, também reavivando o debate entre barbárie e civilização. Em contextos desta natureza, é comum o Estado responder na forma de algum plano emergencial, aí incluídas desde intervenções na ordem econômica a propostas de mudanças mediante novas leis e/ou o aumento ou endurecimento das penas existentes, sugerindo como solução a prevalência de um Estado punitivo. São medidas que visam intervir no sentido de reforçar a afirmação de eficácia da atuação policial e assegurar um certo anestesiamento quanto ao clima de medo e insegurança que, nesses contextos, toma conta da população que contesta, fazendo face às representações de vazio de autoridade e à inexistência do aparato legal. 
Exemplos desse tipo ocorreram ao final de 2007, no Distrito Federal, quando um professor de educação física, embriagado, provavelmente drogado e participando de um pega, provocou a morte de três mulheres, em uma das pontes da cidade, ao se chocar, em alta velocidade, contra o carro onde elas se encontravam. A onda de protestos, passeatas e movimentos teve na mídia espaço privilegiado de expressão e, como resposta, um pacote antiviolência no trânsito, com o qual as autoridades respondiam às "acusações" de conivência com a impunidade. O motorista em questão foi preso, depois solto em função de habeas corpus, posteriormente, preso outra vez e, atualmente (outubro de 2009), encontra-se em liberdade, esperando para ser julgado.

O problema, em casos deste tipo, é a ausência de continuidade das políticas: passado o impacto do acontecimento e do noticiário, sempre potencializado se o acontecido é na capital federal, retomamse os padrões anteriores de (falta de) efetividade, nada mudando - o que aponta para alguns outros aspectos que merecem igual reflexão.

Em primeiro lugar, o caráter tópico e emergencial de boa parte dessas intervenções governamentais seguido da prioridade acordada aos conteúdos "objetivos" das políticas de segurança pública, tais como aumento e aperfeiçoamento do efetivo e das viaturas, a modernização dos procedimentos burocráticos, ou seja, medidas que compartilham da efemeridade da própria notícia e se fazem quase sempre em detrimento daqueles conteúdos considerados subjetivos, aqueles que a população formula sobre violência, segurança ou insegurança pública, polícia, justiça, violência policial. Esses conteúdos estão presentes nas representações sociais elaboradas e produzidas não apenas pelos componentes da área de segurança pública (quer se trate das elites formuladoras destas políticas ou dos policiais, seus comandados, que as executarão), mas, igualmente, por aqueles que direta ou indiretamente se beneficiam ou sofrem as 
consequências dos acertos ou desacertos de tais políticas, ou seja, a sociedade, em seus distintos segmentos. E não apenas no calor da hora, quando clamores recobertos de emoção, medo, dor e raiva tornam-se mais agudos, mas, igualmente, em momentos menos turbulentos, colhidos através de investigações que possam subsidiar ações e políticas públicas. A importância de tais representações decorre de seu sentido prático, já que orientador de condutas.

Inicio a apresentação destes conteúdos relembrando frases do tipo "Brasília não é mais a mesma", "a ilha da fantasia" se integrou e se entregou ao caos urbano, "aqui tudo acaba em pizza". São frases que vêm se tornando corriqueiras no senso comum candango, caracterizando uma das muitas representações sociais estereotipadas, e que, usadas para definir a cidade, dificultam a percepção de que a capital federal é, à semelhança de qualquer outra região do País, um espaço de ambiguidades, heterogeneidades, desigualdades e paradoxos. Considerando-se área de segurança pública, o Distrito Federal apresenta situação privilegiada. Sua organização administrativa, com ausência de autoridades municipais e a centralização da coordenação da política na Secretaria de Segurança minimiza, embora não elimine, conflitos como os que ocorrem em outros Estados, entre prefeitos e governadores.

Segundo dados da Secretaria Nacional de Segurança Pública (Senasp), o Distrito Federal é a unidade da federação com o maior número de policiais, comparativamente à população: “Em 2003, havia um policial militar para cada 137 habitantes do DF, número muito inferior à média nacional (453); também se comparado a outros países, o número é equivalente" (Costa, Bandeira, 2007). Em termos de orçamento, este privilégio se repete, com desdobramentos em termos salariais mostrando que, no DF, um policial pode chegar a receber três vezes mais do que o policial carioca. Segundo dados fornecidos, em 21 de outubro de 2007, por um comandante do BopeDF ao Correio Braziliense (jornal de maior circulação na cidade, 
com cerca de 70 mil assinantes), o salário de um policial do Rio de Janeiro, na época, era de $\mathrm{R} \$ 900,00$ contra $\mathrm{R} \$ 3.500,00$ em Brasília. Esses números parecem sugerir uma situação privilegiada também em termos das taxas de violência e criminalidade no Distrito Federal. Não é, no entanto, o que dizem os dados nem é por aí que caminham as representações sociais candangas.

Vários e distintos cenários têm contribuído para a construção do medo e da insegurança como representações recorrentes do panorama urbano da capital federal. Por um lado, crimes com requintes de crueldade, cujos protagonistas são jovens dos segmentos das camadas médias e ricas da população, acima referidos, suscitam imagens e representações fortes; já embates entre gangues, casos emblemáticos de manifestações de violência policial, violências interpessoais, rixas entre vizinhos e violência doméstica contra mulheres e crianças, em distintos níveis socioeconômicos e culturais - ainda que insiram Brasília no contexto das cidades mais violentas do país -, por seu caráter "corriqueiro", são menos susceptíveis de gerar representações emblemáticas e apenas ocupam o campo dos dados estatísticos e as tradicionais páginas policiais. Por outro lado, também no âmbito das práticas geradoras de estatísticas e de páginas policiais, a articulação crescente entre drogas e armas aí incluídos o tráfico, o consumo o contrabando, contexto para o qual o sistema de segurança pública local se acha completamente despreparado -, tem transformado o Distrito Federal no centro das atenções, expandindo o clima de insegurança, sobretudo nas regiões do entorno, e potencializando a cultura do medo para Brasília como um todo. Ou seja, estas são situações que atingem distintas camadas sociais em âmbito planetário (apesar das diferenças) e nada têm de específicas no Distrito Federal.

O jornal Correio Braziliense realizou, no segundo semestre de 2007, uma série de reportagens, sob o título "Tráfico, extermínio e medo", expondo aspectos centrais da questão da violência e da 
fragilidade a que se encontrava (e se encontra) submetida a população do entorno de Brasília, com as consequências daí decorrentes para o conjunto da região. ${ }^{8}$

$\mathrm{O}$ entorno pertence juridicamente (de direito) ao Estado de Goiás, mas, de fato, está inserido no Distrito Federal, já que é composto por cidades-dormitório, cuja população depende do emprego e dos equipamentos urbanos mínimos (segurança, saúde, lazer, educação) - ou da falta deles - existentes no Distrito Federal. Os governos das duas áreas disputam quando se trata de atribuir deveres e responsabilidades ou de apontar falhas e culpados pelo vazio político administrativo predominante na região, que já foi chamada de "baixada federal". A região é controlada por traficantes que dividem espaços e poderes, levando o ministro do Planejamento a declarar, em 2008, que o IBGE não consegue concluir seu levantamento de dados por não ter acesso à área; ou seja, é como se a estrutura do crime estivesse no controle.

As disputas administrativas impedem ou dificultam que os governos das duas regiões trabalhem em parceria na definição de estratégias, o que, certamente, contribuiria para reverter a atual situação de ausência do poder público.

É intenso o noticiário sobre a violência na região: compreende do envolvimento e morte de adolescentes no tráfico à morte de policiais no exercício de suas atividades (ou fora desse), das acusações das famílias de vítimas de violência (que não se identificam) sobre envolvimento de policiais com o tráfico de drogas e armas à utilização, para o tráfico, de adolescentes e de modelos, que despertam poucas suspeitas. Na verdade, são contextos explosivos que, no entanto, parecem depender do quão afetam o plano piloto para alcançarem repercussão no plano das políticas. A ausência de mecanismos urbanos de toda natureza recheia o noticiário escrito e televisivo sem, contudo, se transformar em "acontecimento" no sentido jornalístico. 
Assim, o crescimento da violência no Distrito Federal não se caracteriza como fato isolado e, dentre suas múltiplas raízes, destacam-se:

1) as desigualdades sociais e não, como comumente se ouve dizer, a pobreza;

2) a fragmentação social, levando à fragmentação de valores, ressaltando a fragilidade dos vínculos sociais, a qual perpassa distintas camadas sociais;

3) o crescimento desordenado das grandes cidades sem a responsabilização dos governos pelo provimento de equipamentos urbanos - as cidades são dinâmicas e é natural que haja movimentos de população; Brasília, não é diferente, mesmo sendo "patrimônio da humanidade", e, portanto, fatores de atração e repulsão que movimentam outras cidades agem também aqui;

4) consumo e o tráfico de drogas associados quase sempre ao porte e/ou ao tráfico de armas - sob este aspecto, seria urgente encontrar mecanismos mais rígidos ao insuficiente controle do porte e do tráfico de armas, em sua articulação com a corrupção em vários níveis (oficiais, oficiosos, públicos e privados) a ele ligados.

Práticas e representações que se interpenetram e se articulam, produtoras e produtos de uma dada realidade que, insisto uma vez mais, espelham grande homogeneidade diante de outras grandes metrópoles. Entretanto, o que parece relevante - justificando o fato deste artigo ressaltar episódios de violência envolvendo jovens de estratos economicamente privilegiados -, é o fato de esses episódios concentrarem as representações sociais que "constroem" Brasília como a ilha da fantasia, habitada por um contingente de privilegiados. 
É o caso, por exemplo, do tratamento dado à questão da impunidade. Os exemplos se multiplicam na cena socioeconômica, mas, de modo geral, os que são valorizados pela mídia dizem respeito à proximidade com o poder, tendo Brasília como lócus privilegiado.

De modo geral, tanto a impunidade, concretamente existente e testemunhada no cotidiano da sociedade, quanto suas representações, como prática corriqueira, conduzem, ainda que não de modo isolado, à produção de situações de imprevisibilidade e de comprometimento das formas de solidariedade vigentes. Contribui para a eliminação de espaços públicos de discussão e de negociação de conflitos, deixando revolta ou violência como horizontes próximos, espécie de estratégia para fazer face ao reino do imprevisível e do caos. Em outras palavras, a subjetividade dos indivíduos interfere tanto quanto a objetividade do fenômeno nos processos de organização das ações e das relações sociais. Se a cidade se concebe como o reino da impunidade, isso interfere nas formas de agir e de interagir socialmente.

Na prática, a prevalência da impunidade ou a onipresença de sua representação - por exemplo, a afirmação de que aqui "tudo acaba em pizza" - tende a colocar em ação uma espécie de lógica do "tudo ou nada", do "ele ou eu" e, ainda, do "se ele pode, por que não eu?" - lógica essa que abre espaço à violência, utilizada como forma de proteção.

Ainda com relação à questão da impunidade, dois episódios ocorridos no Distrito Federal são significativos para nossa argumentação.

Em 2 de dezembro de 1999, segundo notícia do Correio Braziliense, foi registrado um dos episódios mais truculentos da historia da capital: de um confronto entre 146 policiais e cerca de 600 servidores públicos da Novacap ${ }^{9}$ que reivindicavam melhores 
salários, resultou uma pessoa morta e 38 feridas (das quais, duas perderam a visão). Quase oito anos depois, nenhum culpado pela violência tinha sido condenado pela justiça (Correio, 29/07/07).

O segundo exemplo aconteceu no dia 12 de março de 2008, depois da deflagração de uma crise na cúpula da segurança pública, quando o comandante-geral da Polícia Militar foi destituído do cargo, acusado de improbidade administrativa e impunidade com relação a alguns de seus comandados. As denúncias incluíam o envolvimento com bandidos, venda de armamentos e, até mesmo, homicídio. A crise se acirrou e culminou no carnaval de 2008, quando cenas de violência policial foram manchete dos principais jornais televisivos e impressos.

Se os problemas vinham de longa data, apenas tiveram desfecho quando as rotinas de produção jornalística pautaram o assunto, que ganhou visibilidade e, então, o fato se transformou em acontecimento, ganhando contornos de problema político. Antes que a crise na segurança pública se tornasse combustível para a insegurança social e política, a resposta veio através da destituição do comandante-geral da polícia militar.

Um desdobramento desta mesma questão da impunidade retoma, uma vez mais, a representação da cidade como "ilha da fantasia" para testemunhar a internalização por setores da corporação policial da representação de impunidade da qual se beneficiariam os "poderosos". ${ }^{10}$ Dois depoimentos são, nesta perspectiva, exemplares e repõem a dicotomia na forma de tratamento de pobres e ricos. $\mathrm{O}$ primeiro enfatiza justamente esse tratamento desigual em contextos urbanos diferenciados:

[...] Porque a sociedade de baixa renda, no caso aqui o pessoal da Ceilândia, Recanto, Samambaia, trata a polícia assim bem com o nível lá em cima. Vamos falar que eles agradecem a nossa presença lá. Aqui no $\mathrm{Lago}^{11}$ é diferente, aqui você mexe com filho de promotor, filho de juiz, filho de desembargador e aqui não acontece 
nada. Lá não, lá nós somos bem tratados, o pessoal gosta da presença da polícia, é bem diferente. (Policial militar, oficial, participante de grupo focal. Brasília, 2008).

O segundo também registra a diferença e, em ambos os casos evidencia-se, para o bem ou para o mal, o peso que as representações socais da população civil podem ter sobre as práticas policiais, quando nada por interferirem em sua auto avaliação identitária:

[...] porque, às vezes, você prende alguém aqui no Lago, em situações legais a gente faz uma prisão e, na delegacia às vezes aquele cara se admira de você, porque é filho de um ministro ou deputado. Já lá na Ceilândia, você prende, faz tudo corretinho e o cara realmente fica preso. E a população fica grata por isso. Porque é um marginal, realmente que tinha lá. Então existe uma diferença. (Policial militar, sargento, participante de grupo focal. Brasília, 2008).

Já no que diz respeito à violência policial, as ambiguidades no equacionamento da questão, longe de se limitarem às instituições públicas da área de segurança, também permeiam as representações da sociedade civil. Assim, se por um lado, o policial é apontado, seguidas vezes, como fonte de condutas violentas, transgressoras e violentadoras dos direitos humanos, por outro, dele é demandado e cobrado para que atue com mais efetividade, inclusive com utilização de violência, se esta for a condição para manter a ordem, levando-o, de algum modo, a internalizar representações produzidas no âmbito da sociedade, como informa o depoimento de um policial militar:

Às vezes, a imagem que a sociedade tem de que o policial é violento, o policial é bruto, truculento - o policial internaliza isso, muitas vezes, e começa a agir daquela forma. A forma que olham para ele, ele começa a agir daquele jeito e acha normal, tranqüilo (Policial militar, oficial, grupo focal, Brasília, 2008).

Estas representações apelam para o fato de que, inserido em uma sociedade violenta, o policial se deixa contaminar por essa cultura, absorvendo e desenvolvendo uma cultura policial na qual predominam conteúdos que valorizam a violência, inclusive como 
forma de reconhecimento social, conforme já trabalhado em texto anterior (Porto, 2004).

São representações que apontam para a deflagração de uma reciprocidade perversa entre sociedade civil e organizações policiais em função da qual a polícia tende a orientar condutas violentas a partir do que ela supõe que a sociedade espera dela como responsável pela lei e pela ordem.

\section{Considerações finais}

Do ponto de vista que se está aqui privilegiando, determinadas representações sobre o espaço do poder, por vezes, transformam em acontecimento e notícia fatos que passariam despercebidos em outros espaços sociais e silenciam alguns que, talvez, fossem tratados como casos de polícia corriqueiros.

Realçando o componente simbólico que forma e reproduz representações vale, pois, insistir na relevância de tomá-las como material empírico, matéria-prima para a análise sociológica. Das várias dimensões das práticas e das representações da violência aqui tratadas, alguns de seus componentes têm origem na distância e na desconsideração sobre o que dizem as representações sociais, e outros, no super dimensionamento dessas mesmas representações. Assim, para retomar uma afirmação do início do artigo, a crise na/ da segurança pública, se existente (tal avaliação foge aos objetivos do artigo), estaria afeta ao descolamento entre as expectativas da sociedade, tal como formuladas por meio das Representações Sociais, e as respostas dadas, tal como encaminhadas por meio das políticas. O que ocorre é uma ausência de priorização, para não dizer um desconhecimento efetivo dos conteúdos dessas representações elaboradas tanto por atores da sociedade civil quanto por segmentos do aparato de segurança e disseminadas na sociedade brasileira. 
Os distintos exemplos aqui abordados buscaram ressaltar a importância de que as representações sociais, juntamente com as estatísticas e os dados, ditos objetivos, sejam integrados aos conteúdos que subsidiam a políticas públicas para a área de segurança. A condição de falsa ou verdadeira de uma dada representação social é irrelevante; ao invés disso, importa considerar que as afirmações nela contidas estão difundidas no senso comum, fazem parte dos ditos populares e - o que é mais importante -, uma vez constituídas como verdade, informam condutas e comportamentos dos atores sociais, aí incluídos possíveis formuladores de políticas públicas.

No contexto da capital federal, é pertinente supor que a articulação práticas/representações sociais, na condição de subsídio à compreensão da realidade, será um instrumento valioso para a relativização, ou, melhor dizendo, para o dimensionamento de determinados estigmas que, colados à imagem da cidade, passaram a ser percebidos como verdades. Sem minimizar as manifestações recentes de violência que o Distrito Federal tem protagonizado gostaria de pontuar melhor a questão, lembrando que o crescimento da violência não é um fato característico apenas de Brasília ou do Brasil; é um fenômeno planetário e, está presente em alguns grandes centros. Não convém esquecer que, sob esse aspecto, Brasília, era, até há pouco, uma pequena cidade e vem assumindo características de grande metrópole, com nível de vida e poder aquisitivo superiores ao de várias outras capitais brasileiras e com manifestações de violência, como as mencionadas anteriormente, que em tudo se assemelham a crimes e violências típicas de contextos nos quais as possíveis causas para atos dessa natureza nada têm a ver com a sobrevivência e se repetem em distintos contextos societários. Em Brasília, entretanto, a proximidade do poder, torna-a mais visada pois representada no imaginário popular como o reino da impunidade, da corrupção. Em outras cidades, as situações de impunidade envolvendo justiceiros, assassinatos, mandantes, representantes do crime organizado, linchamentos, fazem vítimas anônimas e, portanto 
com menor visibilidade. Aqui os atores, tanto quanto as vítimas, quase sempre têm nome, endereço e status social conhecido: o filho ou a filha de tal ou qual deputado, senador, ministro, funcionário, etc. potencializando representações de atipicidade.

Como tenho insistido em várias oportunidades e correndo o risco do exagero, poder-se-ia talvez até afirmar que, quando se trata de fazer avançar o conhecimento de um dado fenômeno, no caso o da violência, interessa menos o fato e mais suas representações, orientadoras do agir dos atores sociais. Buscando o equilíbrio, entretanto, talvez fosse mais sensato dizer que interessam tanto o fato quanto as suas representações.

Desta perspectiva, reverter o cenário de algumas das situações evidenciadas demandaria talvez a busca de mecanismos que promovessem maior proximidade entre os órgãos de segurança pública e a sociedade, de modo a captar os ecos das representações sociais elaboradas por distintos segmentos da sociedade civil, assim como pelos representantes do Estado, encarregados de prover lei e ordem sem abrir mão da garantia dos direitos humanos, desafio maior das modernas democracias.

\section{Notas}

1 Para a análise desta questão, cf. Beato (1995), Coelho (2005), Misse (1995), Paixão (1995), Zaluar (1994), entre outros.

2 Sessão elaborada com base em Porto (2000, 2006, 2009).

3 Para esta análise, cf. Nunes (2004) e Ribeiro (2008).

4 Esta sessão se vale, em larga medida, de conteúdos apresentados em Porto (2003, 2009b).

5 Nesse episódio, cinco jovens, sendo um menor, jogaram álcool e atearam fogo no índio pataxó Galdino Jesus dos Santos, que dormia em 
um ponto de ônibus, queimando-o vivo e ocasionando sua morte. $\mathrm{O}$ fato aconteceu a 20 de abril de 1997, véspera do Dia do Índio.

6 Marco Antônio Velasco morreu a 11 de agosto de 1993, espancado por uma gangue de lutadores de artes marciais; João Cláudio Cardoso Leal foi assassinado por um grupo de jovens no dia 9 de agosto de 2000 e Rodrigo Toledo de Aguiar, de 18 anos, foi morto, também por uma gangue, no dia 21 de abril de 2001.

7 Assassinato ocorrido em 17 de setembro 2002, em Porto Seguro, quando sete jovens brasilienses, sendo dois menores de idade, espancaram o garçom Nelson dos Santos, de 39 anos, sem lhe dar possibilidade para se defender, e, como consequência do espancamento, ele veio a falecer.

8 Para maiores detalhes sobre a configuração socioespacial e econômica da região, cf. Porto (2009b).

9 Companhia de urbanização da nova capital, surgida com a construção de Brasília.

$10 \mathrm{O}$ condicional quer aqui insistir no fato de que, do ponto de vista da análise sociológica, não está aqui em questão "apurar" o caráter de falsidade ou veracidade da afirmação.

11 Regiões Administrativas do Distrito Federal, estando as três primeiras situadas dentre as regiões de mais baixo poder aquisitivo e a última, o Lago (no caso o Lago Sul) considerada, juntamente com o Lago Norte, regiões nobres da cidade, concentrando as populações de rendas mais elevadas do Distrito Federal.

\section{Brasilia, a city like others? Social representations of violence practices}

Abstract: Privileging the analysis of the social representations means to recognize its theoretical-methodological importance as a strategy of knowledge of the society. Considering its theme, the article explicits the pertinence of the Theory of the Social Representations 
as a possible analysis of the phenomenon of the contemporary violence, assuming the impossibility of understanding it without asking oneself about the senses, values and beliefs that structure and preside the social life. The text emphasizes the importance that public safety policies take into consideration meanings and senses, of subjective nature, expressed in the Social Representations, elaborated and produced not only by the members of public safety area but, equally, by those who direct or indirectly benefit or suffer from the consequences of their successes or mistakes. i.e., the society, in their different segments. In other words, through the use of empiric evidences, one points out the pertinence of inserting the theme of the social representations and of their contents in the horizon of the concerns of policy makers. The Federal District is the empiric universe that gives support to the accomplished analyses.

Keywords: practices and social representations; public safety; violence; fear; Federal District.

\section{Referências bibliográficas}

ACKERMANN, W,; DULONG, R.; JEUDI, H. P. (Orgs). Imaginaires de l'insécurité. Paris: Librarie des Meridiens, 1983.

ADORNO, S. Monopólio estatal da violência na sociedade brasileira contemporânea. In: MICELLI, S. (Org.). O que ler na ciência social brasileira. São Paulo: Sumaré; Brasília, DF, Capes, 2002.

ADORNO, Sergio; LAMIM, Cristiane. Medo, violência e insegurança. In: LIMA, Renato Sérgio; PAULA, Liana. (Orgs.). Segurança pública e violência: o Estado está cumprindo o seu papel? São Paulo: Contexto, 2006.

BEATO, Cláudio. Determinantes da criminalidade em Minas Gerais Revista. Brasileira de Ciências Sociais, São Paulo, v. 13, n. 37, 1998.

CHEVALIER, Louis. Classes laboureuses et classes dangeureuses. Paris: Hachette, 1984. 
COELHO, Edmundo Campos. A Oficina do Diabo e outro estudos de criminalidade. Rio de Janeiro: Record, 2005.

CORREIO Braziliense [Jornal], Brasília, edições diversas entre out. 2007 e abr. 2008.

COSTA, A. M.; BANDEIRA. L. M. (Orgs.). A segurança pública no Distrito Federal. Brasília: LGE, 2007.

COSTA. A. M.; PORTO, M. S. G. Condutas policiais e códigos de Deontologia: um estudo comparativo sobre as relações entre polícia e sociedade. Brasília: Ministério da Justiça, Relatório Final de Pesquisa, 2005.

DURKHEIM, Èmile. Representações individuais e representações coletivas. In: . Sociologia e Filosofia. Rio de Janeiro: Forense Universitária, 1970.

FARR, R. M. Representações sociais: a teoria e sua história. In: JOVCHELOVITCH, S.; GUARESCHI, P. (Orgs.). Textos em representações sociais. Petrópolis: Vozes, 1994.

FARR, R. M.; MOSCOVICI, S. (Ed.). Social Representations. Cambridge: Cambridge University Press; Paris: Maison des Sciences de l'Homme, 1984.

JODELET, D. Représentations sociales: un domaine en expansion. In: JODELET, D. (Org.). Les représentations sociales. Paris: Presses Universitaires de France, 1989.

. Représentation sociale: phénomènes, concept et théorie. In: MOSCOVICI, S. (Dir.). Psycologie sociale. Paris: Presses Universitaire de France, 1984. p. 357-378.

. Representações sociais: um domínio em expansão. In: JODELET, Denise (Org.). As representações sociais. Rio de Janeiro: Ed UERJ, 2001.

MICHAUD, Y. A violência. São Paulo: Ática, 1989.

. La violence apprivoisée. Paris: Hachette, 1996. 
MINAYO, M. C. de S. O conceito de representações sociais dentro da Sociologia Clássica. In: JOVCHELOVITCH, S.; GUARESCHI, P. (Orgs.). Textos em representações sociais. Petrópolis: Vozes, 1994.

MISSE, Michel. Crime e pobreza: velhos enfoques, novos problemas. In: VILLAS-BOAS, Gláucia; GONÇALVES, M. A. (Orgs.). O Brasil na virada do século. Rio de Janeiro: Relume-Dumará, 1995.

MOSCOVICI, S. Des représentations collectives aux représentations sociales: éléments pour une histoire. In: JODELET, D. (Org.). Les représentations sociales. Paris: PUF, 1989.

. Prefácio. In: JOVCHELOVITCH, S ; GUARESCHI, P. (Orgs.). Textos em Representações Sociais. Petrópolis: Vozes, 1994.

. Representações sociais: investigações em Psicologia Social. Petrópolis: Vozes, 2003.

MUNIZ, J. Direitos humanos na polícia. In: LIMA, R.; PAULA, L. (Orgs.). Segurança pública e violência: o Estado está cumprindo seu papel? São Paulo: Contexto, 2007.

NUNES, F. B. Brasília. A fantasia corporificada. Brasília: Paralelo 15, 2004.

PAIXÃO, A. L. Crime, controle social e a cultura oficial da sociologia. Sociedade e Estado, v. 10, n. 02, jul./dez. 2005.

PORTO, M. S. G. Re-pensando crenças e valores: sociologia representações sociais. In: ALMEIDA, A. M. O.; JODELET, D. (Orgs.). Interdisciplinaridade e diversidade de paradigmas. Brasília: Thesaurus, 2009.

- Realidade, representações sociais e segurança pública: uma interpretação. In: MENEZES, J. (Org.). Segurança pública: representações sociais e políticas de formação. São Cristovão: Editora UFS, 2009.

- Violência e meios de comunicação de massa na sociedade contemporânea. Sociologias, Porto Alegre, v. 4, n. 8, jul./dez. 2006. 
PORTO, M. S. G. Polícia e violência: representações sociais de elites policiais do Distrito Federal. S. Paulo em Perspectiva, revista da Fundação Seade, v. 18, n.1, p. 132-141, jan./mar. 2004.

. O novo endereço da violência. UnB Revista, v. 3, n. 7, jan./mar. 2003.

. A violência entre a inclusão e a exclusão social. Tempo Social, Revista de Sociologia da USP, São Paulo, v. 12, n. 1, p. 187-200, 2000 .

RIBEIRO, G. L. O capital da esperança: a experiência dos trabalhadores na construção de Brasília. Brasília: ed. UnB, 2008.

WEBER, M. Economia e sociedade. Brasília: Ed. UnB, v. 1, 1991.

. Ética protestante e o espirito do Capitalismo. São Paulo: Cia. das Letras, 2004.

WIEVIORKA, M. Culture, société et démocratie. In: WIEVIORKA, M. Une societé fragmentée? Le multiculturalisme en débat. Paris: La Découverte, 1997.

. O novo paradigma da violência. Tempo Social, v. 9, n. 1, maio 1997.

. Em que mundo viveremos? São Paulo: Perspectiva, 2006. 